\title{
Occupation and male infertility: glycol ethers and other exposures
}

\author{
N Cherry, ${ }^{1}$ H Moore, ${ }^{2}$ R McNamee, ${ }^{1}$ A Pacey, ${ }^{2}$ G Burgess, ${ }^{1}$ J-A Clyma, ${ }^{1}$ M Dippnall, ${ }^{1}$ \\ $\mathrm{H}$ Baillie, ${ }^{2}$ A Povey, ${ }^{1}$ participating centres of Chaps-UK
}

${ }^{1}$ Centre for Occupational and Environmental Health, University of Manchester, UK; ${ }^{2}$ Academic Unit of Reproductive and Developmental Medicine, University of Sheffield, UK

Correspondence to:

Nicola Cherry, Community and Occupational Medicine Program, 13-103 Clinical Sciences Building, University of Alberta, Edmonton Alberta, Canada T6G 2G3; nicola.cherry@ualberta.ca

For participating centres see end of article

Accepted 31 January 2008

Published Online First

3 April 2008

\section{ABSTRACT}

Objectives: To investigate the relation between male infertility and occupational exposures, particularly glycol ethers.

Methods: A case-referent study was designed in which men attending 14 fertility clinics in 11 centres across the UK in 1999-2002 were recruited following 12 months of unprotected intercourse and without a previous semen analysis. Cases were those with low motile sperm concentration (MSC) relative to the time since their last ejaculation (MSC $<12 \times 10^{6}$ for 3 days of abstinence). Referents were other men attending these clinics and meeting the inclusion criteria. A single semen sample was collected at the clinic and analysed at the andrology laboratory serving each hospital. Concentration was determined manually with motility assessed centrally from video recordings. Exposures and confounding factors were assessed from self-completed and nurse-interviewer questionnaires, completed prior to the results of the semen analysis. The occupational histories were assessed for exposures relative to UK norms by a team of occupational hygienists blind to case status.

Results: Of 2118 men in employment at the time of the interview, 874 (41.3\%) were cases. Work with organic solvents, particularly glycol ethers, in the 3 months before the first clinic visit was associated with the likelihood of low motile sperm count. Unadjusted odds ratios (OR) for moderate and high glycol ether exposure (compared with none) were 1.70 (95\% Cl: 1.11 to 2.61$)$ and 2.54 (95\% Cl: 1.24 to 5.21). Adjustment for potential confounders (surgery to the testes, previous conception, wearing boxer shorts, drinking alcohol, employed in manual work) reduced the risk associated with glycol ether exposure: moderate $\mathrm{OR}=1.46$ (95\% $\mathrm{Cl}$ : 0.93 to 2.28$)$, high $\mathrm{OR}=2.25$ (95\% Cl: 1.08 to 4.69$)$. No other occupational risk factor was identified.

Conclusions: Glycol ether exposure was related to low motile sperm count in men attending fertility clinics. This suggests that, at the time of the study, glycol ethers continued to be a hazard for male fertility.

It has been recognised for many years that occupational exposure to lead could affect male fertility at sufficiently high doses. ${ }^{1}$ The discovery that dibromochloropropane (DBCP), a nematocide used particularly in sub-tropical climates, could induce azoospermia ${ }^{2}$ raised concerns that other chemical compounds might affect spermatogenesis. $^{3}$ A relatively small number of substances particularly pesticides (for example, keptone ${ }^{4}$ and ethylene dibromide ${ }^{5}$ ), organic solvents (for example, carbon disulphide ${ }^{6}$ ) and physical agents (heat ${ }^{7}$ and driving ${ }^{8}$ ) were identified as possibly influencing parameters (count, motility or morphology) measured in routine semen analyses. The publication of data suggesting that sperm count had decreased, and was continuing to decrease, in more industrialised countries fostered speculation that previously unrecognised occupational and environmental factors might affect fertility. ${ }^{910}$ This heightened awareness of possible environmental toxicants encouraged investigation, using improved semen measurement, of exposures suspected to be capable of affecting sperm. ${ }^{11}$

The study reported here was designed primarily to test one a priori hypothesis, that organic solvents, and specifically solvent mixtures containing glycol ethers, were associated with a reduced number of motile sperm. This hypothesis had arisen from an earlier study, ${ }^{12}$ which suggested that amongst men attending fertility clinics those who were found to have a low motile sperm count were more likely to have been exposed to organic solvents than men with moderate or high counts.

\section{METHODS}

\section{Design}

This was a multi-centre, case-referent study where cases and referents were male patients identified at or before the first visit to the same fertility clinic. To be included in the study, both cases and referents had to be part of a couple seeking a conception but without success, following at least 12 months of unprotected intercourse and, importantly, to have had no previous semen analysis. Cases were men with low motile sperm concentration (MSC) relative to the number of days since last ejaculation. For men with three days' abstinence an MSC of $<12 \times 10^{6} / \mathrm{ml}$ was used to define a case; cut-offs for other abstinence groups are given below. This a priori case definition was based on an earlier study ${ }^{12}$ of solvents and male fertility and reflected the WHO recommendations ${ }^{13}$ then in place for "normal" sperm count $\left(20 \times 10^{6} / \mathrm{ml}\right)$ and motility (60\%). Referents were the other men meeting these criteria and recruited to the study whose semen sample was not found to have a low MSC in relation to days of abstinence.

\section{Recruitment of subjects}

Men were recruited from 14 fertility clinics across the UK during a 37-month period from 1st January 1999. The methods used for recruitment differed according to the practice of each clinic, with men recruited at the first visit to a fertility or gynaecology clinic, at the time of the first visit to an andrology laboratory for semen analysis or when a first appointment was made for a semen 
analysis. In each case the study was explained briefly and consent sought for the research team to contact the subject. If he agreed, a package was sent to his home containing information sheets and a brief questionnaire to be completed should he agree to take part. He was requested to abstain from ejaculation for a period of 3-5 days (depending on the clinic) prior to the clinic visit. On presentation at the clinic for the first appointment following consent, the subject was interviewed by a research nurse to elaborate on the information contained in the pre-interview questionnaire. He also gave blood, urine and semen samples.

\section{Collection and analysis of semen samples}

All men recruited to the study provided a semen sample for a diagnostic procedure as part of infertility investigations with their partner. The same sample was used for the research study. It was collected at the clinic into a standard plastic container and analysed following the protocol summarised in Figure 1, based on the techniques outlined in the World Health Organization (1999) manual. ${ }^{14}$ The analyses were carried out in 12 andrology laboratories associated with 14 hospital clinics; each was a member of the semen analysis scheme of the United Kingdom National External Quality Assessment Service (UKNEQAS). Sperm concentration was estimated at each site using a haemocytometre on a single dilution made in each laboratory at the time of semen analysis. Motility was captured on video tape using a computer outstation commissioned for the study from Hobson Tracker Systems Limited, Sheffield, UK, and the tape was returned to the central laboratory for analysis of sperm motility by Computer Assisted Sperm Analysis (CASA). The proportion of motile sperm was calculated as the percentage of sperm moving forward at 5 microns/second or greater.

\section{Occupational exposure assessment \\ Self-report}

Before the interview the subject completed a questionnaire on which he recorded a complete job history and exposures during the last 2 years to a number of chemicals, tasks, physical agents and activities. The answers to these questions, referred to below as self-reported exposures, were recorded simply as "exposed" or "not exposed". At the interview the research nurse checked the completeness of the answers to this questionnaire, recorded answers to any that had been missed, and conducted the detailed occupational interviews described below. In every case this was completed before the result of the semen analysis was available.

\section{Job-specific questionnaires}

Thirty job-specific questionnaires were designed for this study. Interviewers were trained to administer one of these questionnaires if any of 100 job titles occurred in the occupational history reported by the subject. The job-specific questionnaires concentrated on tasks, controls and personal protection rather than asking about chemical or physical exposures, and were designed to allow exposures to be assessed by the occupational hygienists from the information recorded by the nurse rather than from the subject's own account of recalled or perceived exposures.

\section{Exposure assessment by professional occupational hygienists}

The complete set of questionnaires (self-completed, nurse interview and job-specific questionnaires) was first reviewed by the study hygienist (MD). If no exposure was reported and it was considered highly unlikely that any exposure had occurred, given the job titles and information from any job-specific questionnaires, the subject was considered unexposed and the information was not assessed further. For all subjects designated from this initial review to have possible exposure, the forms were examined independently by two of a panel of eight professional hygienists, each with at least 10 years' experience in the field of occupational hygiene and who was a Member or Fellow of the British accrediting body for occupational hygiene. The hygienists assessed exposure to four metals (lead and mercury - both organic and inorganic - manganese and boron) and "all other metals", five solvents (carbon disulphide, glycol ethers, methylene chloride, styrene and tetrachloroethylene) and "all other volatile organic compounds (VOC)", and five other exposures (pesticides, heat, vibration and radiation both ionising and non-ionising). All exposures were chosen, following review of the relevant literature, as having some evidence of a possible effect on male fertility.

For each exposure the hygienist first decided whether, in his or her professional judgement, exposure was likely to be present at more than background levels; if so, a number of parameters of exposure (including route and intensity) were assessed. In the analyses reported here, the intensity of exposure was considered in relation to others exposed in the UK; a man was assessed as having high exposure if his average exposure to a specific metal, solvent or other factor was likely to have been at levels found only in the highest third of those exposed in the UK, and low if it was in the lowest third of those with exposure. These assessments were made for three periods before the semen sample was collected: the three months immediately prior to collection, the three months before that and for the previous 18 months. Exposure assessments thus covered the 24 months prior to the semen sample. In this report, considering in particular solvents, rapidly metabolised and excreted, only exposures during the 3 months prior to the sample were considered. For each substance or factor, the higher of the independent ratings from the two hygienists was taken as representing the exposure of that man to that substance.

These ratings estimated exposure for 18 substances in four main classes: metals, volatile organic compounds (solvents), pesticides and physical factors (heat, vibration, radiation). In order to consider the relative importance of glycol ethers and other solvent exposure, which was of particular interest to this report, a new factor was also estimated by inspection of the individual ratings for each subject; this reflected the highest exposure to any solvent other than glycol ethers.

\section{Occupation}

The job title of the current or previous job was coded to three digits using the standard occupational classification ${ }^{15}$ used by the UK census and regrouped, using this classification, to manual or non-manual work.

\section{Assessment of potential confounders and effect modifiers}

Information on potential confounders and effect modifiers was collected and has been reported elsewhere (SOC). ${ }^{16}$ Those of potential importance for the current report were age (of subject and spouse), previous conceptions, medical history (particularly of surgery to the testes), use of medications, recreational drugs, tobacco, alcohol and wearing of restrictive underwear. All of this information was obtained from the nurse interviewer, concentrating particularly on the two years prior to the semen sample. 


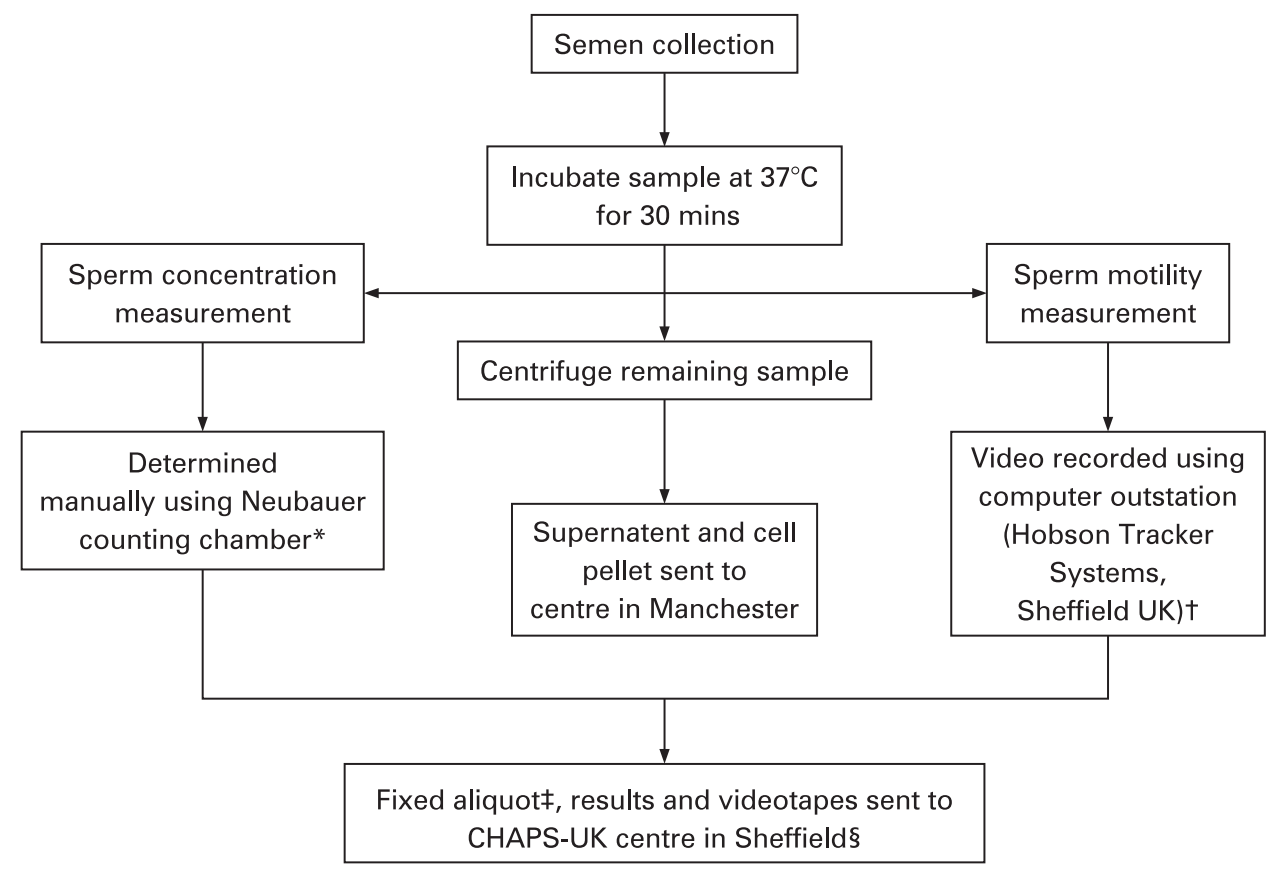

Figure 1 Summary of the semen analysis procedure. Training, documentation, recording forms, equipment and consumables provided centrally. Each site received regular visits to ensure compliance and equipment performance. ${ }^{*}$ Concentration measured on both chamber sides using a single dilution. Samples were recounted from the same dilution if the counts from both sides differed by more than $10 \%$. The dilution and raw data were recorded to enable calculation to be independently checked. †Motility was observed in a $20 \mu \mathrm{m}$ depth MicroCell ${ }^{\mathrm{TM}}$ slide (Conception Technologies, CA, USA); the set-up of the computer outstation was accessible only by the central laboratory at the University of Sheffield. The operator randomly selected the first field to be recorded after which there was automatic sampling for a further seven fields, each being recorded at 20 seconds. Both a neat and a diluted (1:4 in phosphate-buffered saline) aliquot was analysed. $\$$ One in 10 samples was examined centrally by a single experienced technician to monitor laboratory performance. §A Hamilton Thorne VOS version 10.80 (IVOS, Hamilton Thorne Research, Beverly, MA, USA) was used to analyse the sperm motility. The proportion of motile sperm was calculated as the percentage of sperm moving forward at 5 microns/second or greater.

\section{Statistical methods and power}

Following univariate descriptive analysis, unconditional logistic regression analysis was used to estimate the effect of occupational exposures, having allowed for potential confounders. Confounders found in previous univariate analysis related to case status with $p<0.05$ were included in each of the models fitted. Because the observations were clustered within 11 urban centres, a multi-level model was fitted (using gllamm within Stata 9) with centre-specific random intercepts.

The number of subjects needed for $80 \%$ power to detect an odds ratio (OR) of 2 using a 2 -sided significance test and $5 \%$ level of significance were estimated at 2300 assuming a 2:1 ratio of controls to case and that 1 in 40 controls would be exposed.

\section{Ethics}

Ethical approval was given by the Multi-Centre Ethics Committee for the North West (ref. no. MREC 98/8/73) with subsequent approval given by the Local Research Ethics Committee at each site.

\section{RESULTS}

\section{Study participation}

A total of 11680 men with appointments for fertility investigations were reviewed. Of these only 4257 were eligible. Of the remaining 7432 participants, eligibility could not be established in 841 and 6582 were clearly ineligible. More than three-quarters of these (5050/6582) were excluded because, prior to interview, they had undergone a semen analysis (for the current period of infertility) and were aware of the result. Other reasons for exclusion were a period of less than 12 months attempting to conceive $(n=306)$, the couple being currently under treatment (350), only 1 member of the couple undergoing investigation (313), a previous sterilisation (279) or an excluding medical condition (30). Others were excluded because they could not speak English (142) or a pregnancy intervened (112). Among the 4257 eligible cases, $53 \%$ (2249) were successfully recruited, took part in an interview and gave a semen sample. Of those recruited, $68 \%$ were approached at a fertility or gynaecology clinic and $32 \%$ at an andrology laboratory. Of the 2008 not recruited, $67.7 \%$ (1360) refused, 572 did not attend the interview and 76 men completed the interview but did not provide a semen sample.

The analysis reported here was thus based on 2249 subjects, of whom 2118 were in employment at the time of interview (see below).

\section{Semen analysis}

Motile sperm concentration (MSC)

The product of sperm concentration and motility (MSC) was used to define a case in this study. The median MSC for the whole study group was $17.7 \times 10^{6} / \mathrm{ml}$ (range $0-507 \times 10^{6}$ ) and mean $31.2 \times 10^{6} / \mathrm{ml}(\mathrm{SD}=40.6)$, with 182 men $(8.1 \%$ of the study group) having no motile sperm. Of the 2249 subjects, 871 $(38.7 \%)$ met an initial case definition of $<12 \times 10^{6} / \mathrm{ml}$ progressively motile sperm. However, the concentration of motile sperm was strongly related to time since last ejaculation (Table 1) which suggested that the case definition should be revised to take account of abstinence. 
Table 1 Motile sperm concentration by days of abstinence, with cutoff for case definition

\begin{tabular}{|c|c|c|c|c|c|}
\hline \multirow{2}{*}{$\begin{array}{l}\text { Days of } \\
\text { abstinence }\end{array}$} & \multicolumn{3}{|c|}{ Motile sperm concentration } & \multirow{2}{*}{$\begin{array}{l}<12 \times 10^{6} \\
\%\end{array}$} & \multirow{2}{*}{$\begin{array}{l}\text { Cut-off adopted } \\
\left(\times 10^{6}\right) \text { to define a } \\
\text { case (concentration } \\
\text { of motile sperm) }\end{array}$} \\
\hline & Mean & SD & $\mathbf{n}$ & & \\
\hline $0-2$ & 23.2 & 29.7 & 362 & 45.6 & $<10.4$ \\
\hline 3 & 28.9 & 41.5 & 706 & 41.8 & $<12.0$ \\
\hline 4 & 31.8 & 42.0 & 497 & 37.8 & $<13.9$ \\
\hline 5 & 35.4 & 40.6 & 289 & 33.9 & $<15.8$ \\
\hline 6 or more & 38.7 & 44.3 & 390 & 29.0 & $<17.0$ \\
\hline Overall & 31.2 & 40.6 & $2244^{*}$ & 38.8 & - \\
\hline
\end{tabular}

*Five subjects did not have days of abstinence recorded (see text).

\section{Revised case definition}

In those with 3 days' abstinence $41.8 \%$ had an MSC meeting the initial case definition. This percentage was used for the definition of a case in each abstinence group, resulting in a moving cut-off point on the MSC scale (Table 1, column 5). Thus, a subject with 5 days of abstinence (for example) would be a case if his MSC was $<15.8 \times 10^{6}$ (rather than $<12.00 \times 10^{6}$ ). Of the five cases with no record of days of abstinence, one had an MSC of $13.8 \times 10^{6}$; since more than half of those with known abstinence reported four or more days, the balance of probabilities suggested that he be considered a case. The other four had an MSC that implied referent status, regardless of duration of abstinence.

\section{Description of the study population}

There was no important difference between cases and referents either in their own age (cases: mean 33.7, SD 6.5; referents: mean 33.5, SD 5.9) nor that of their spouse (cases: mean 30.8, SD 5.5; referents: mean 31.2, $\mathrm{SD}=5.2$ ). Of the potential confounders considered only five were found to be related to case status. Those with surgery to the testes or in manual work were more likely to be a case and those reporting that they drank alcohol regularly, usually wore boxer shorts or had been responsible for a conception were more likely to be a referent. Cases were no more likely to report smoking cigarettes than referents (cases 38.1\%; referents $37.4 \%$ ). The centre from which the subject was recruited was also examined. The proportion of cases in the different centres ranged from $36.1 \%$ to $47.5 \%$.

\section{Occupational exposures}

The analyses of occupational exposures reported here included only those in employment at the time of the semen analysis. It is thus based on 2118 subjects (874 cases and 1244 referents) and excludes 57 cases (6.1\%) and 66 referents (5.0\%) who were unemployed or students.

\section{Self-reported exposures}

There was no significant difference between cases and referents on any of the 21 exposures in the last 3 months reported by the subject himself (Table 2). Having adjusted for four of the factors found to be significantly associated (either positively or negatively) with case status: surgery to the testes, previous conceptions by the male partner, use of alcohol, wearing boxer shorts, there was some suggestion that exposure to glues or paints, work in stripping paints or driving for more than 4 hours were more common in cases but these differences were compatible with chance.
Table 2 Self-reported exposure in the last 2 years by case status

\begin{tabular}{|c|c|c|c|c|}
\hline & \multirow{2}{*}{$\begin{array}{l}\text { Case } \\
\text { Yes }\end{array}$} & \multirow{2}{*}{$\begin{array}{l}\text { Referent } \\
\text { \% Yes }\end{array}$} & \multirow{2}{*}{$\frac{\text { Total }}{\% \text { Yes }}$} & \multirow[b]{2}{*}{$O R^{*}(95 \% \mathrm{Cl})$} \\
\hline & & & & \\
\hline Metal dust or fumes & 23.8 & 23.3 & 23.5 & 1.04 (0.84 to 1.28$)$ \\
\hline Pesticide or weed killer & 3.9 & 5.2 & 4.7 & $0.69(0.45$ to 1.07$)$ \\
\hline Fertilisers & 3.4 & 3.8 & 3.6 & $0.87(0.54$ to 1.40$)$ \\
\hline Oils or greases & 27.6 & 27.0 & 27.3 & $1.04(0.86$ to 1.27$)$ \\
\hline Detergents or soaps & 28.7 & 26.2 & 27.2 & $1.15(0.94$ to 1.40$)$ \\
\hline Glues, adhesives or resins & 22.7 & 20.5 & 21.4 & $1.17(0.94$ to 1.45$)$ \\
\hline $\begin{array}{l}\text { Paints, varnishes or } \\
\text { lacquers }\end{array}$ & 18.9 & 17.0 & 17.8 & $1.16(0.92$ to 1.46$)$ \\
\hline Printing inks and dye stuffs & s 6.0 & 6.1 & 6.1 & 0.96 (0.66 to 1.39$)$ \\
\hline Dry cleaning fluids & 0.7 & 1.0 & 0.9 & $0.74(0.27$ to 2.02$)$ \\
\hline Other solvents & 23.1 & 23.6 & 23.4 & $0.98(0.79$ to 1.20$)$ \\
\hline Welding & 8.6 & 9.3 & 9.0 & 0.90 (0.66 to 1.22$)$ \\
\hline Metal work & 16.6 & 16.9 & 16.8 & $0.96(0.75$ to 1.21$)$ \\
\hline Electroplating & 0.3 & 0.7 & 0.6 & $0.47(0.13$ to 1.76$)$ \\
\hline Degreasing & 10.1 & 10.8 & 10.5 & 0.93 (0.69 to 1.24$)$ \\
\hline Stripping & 9.9 & 8.7 & 9.2 & 1.17 (0.86 to 1.58$)$ \\
\hline Extremely hot environment & 10.9 & 10.2 & 10.5 & $1.10(0.83$ to 1.46$)$ \\
\hline $\begin{array}{l}\text { Heavy vibration machining, } \\
\text { equipment or vehicles }\end{array}$ & 15.6 & 15.4 & 15.5 & $1.04(0.82$ to 1.33$)$ \\
\hline Non-ionising radiation & 11.6 & 11.5 & 11.5 & $1.00(0.76$ to 1.31$)$ \\
\hline $\begin{array}{l}\text { Driving (and/or driver's } \\
\text { mate) (more than } 4 \text { hours/ } \\
\text { day) }\end{array}$ & 28.8 & 25.6 & 26.9 & $1.20(0.99$ to 1.46$)$ \\
\hline $\begin{array}{l}\text { Flying (more than } 10 \\
\text { flights/year) }\end{array}$ & 5.1 & 5.6 & 5.4 & 0.88 (0.59 to 1.31$)$ \\
\hline $\begin{array}{l}\text { Working underground or } \\
\text { underwater }\end{array}$ & 1.4 & 1.4 & 1.4 & 1.12 (0.53 to 2.37 ) \\
\hline $\mathrm{N}^{* *}$ & 874 & 1244 & 2118 & \\
\hline
\end{tabular}

\section{$\mathrm{OR}$, odds ratio.}

*For each self-reported exposure, "not exposed" is the referent value. ORs have been adjusted, in a multilevel model, for surgery to the testes, previous conception, use of alcohol and wearing boxer shorts, clustered within the centre.

${ }^{* *}$ Missing data ranged from $\mathrm{N}=1$ (for driving) to $\mathrm{N}=18$ (for exposure to detergents or soaps).

\section{Hygienists' assessment of exposure intensity}

At the initial scrutiny by the study hygienist (MD) 646 subjects (260 cases and 386 referents) were assessed as not exposed to any of the factors of interest, were assigned zero exposure on each and included as such in the subsequent analyses. The distribution of 18 exposures (Table 3 ) showed that exposures to most metals, to most VOCs, and to pesticides and ionising radiation (in the last 3 months) were infrequently assessed as present in this study population. No difference was seen between cases and referents even for most of the more common exposures. In the adjusted models, significant differences were seen only for glycol ethers and, with lower significance, "all other volatile organic compounds (VOCs)". Inspection of the adjusted ORs for each class of exposure suggested only two monotonically increasing trends (both non-significant), based on low numbers with exposure to carbon disulphide and styrene. The ORs for these and for the two substances significantly related to case status (glycol ethers and "all other VOCs") are shown in Table 4.

Only 13 of those exposed to glycol ethers had no other solvent exposure (that is, were assessed as zero on the variable constructed to reflect solvent exposures other than to glycol ethers). The extent to which the relation to glycol ethers and to other solvents was confounded was examined by adding the constructed variable reflecting the highest exposure to solvents other than to glycol ether to the regression model. This constructed variable did not add to the model if entered after 
Table 3 Exposures in the 3 months prior to semen sample assessed by the occupational hygiene team from the job questionnaires

\begin{tabular}{|c|c|c|c|c|c|c|}
\hline \multirow[b]{2}{*}{ Exposure } & \multicolumn{5}{|c|}{$\%$ rated as: } & \multirow{2}{*}{$\begin{array}{l}\text { Adjusted model* } \\
\text { p Value }\end{array}$} \\
\hline & None & Low & Medium & High & Total & \\
\hline Lead (organic) & 99.2 & 0.6 & 0.2 & 0.1 & 100.0 & $0.088 \dagger$ \\
\hline Lead (inorganic) & 85.4 & 12.0 & 2.2 & 0.4 & 100.0 & 0.175 \\
\hline Manganese & 84.3 & 12.6 & 2.4 & 0.8 & 100.0 & 0.924 \\
\hline Mercury (organic) & 99.4 & 0.5 & 0.0 & 0.0 & 100.0 & $0.531 \%$ \\
\hline Mercury (inorganic) & 98.4 & 1.0 & 0.3 & 0.2 & 100.0 & $0.156 \dagger$ \\
\hline Boron & 82.8 & 14.7 & 2.0 & 0.6 & 100.0 & 0.296 \\
\hline All other metals & 79.2 & 15.2 & 3.7 & 1.9 & 100.0 & 0.720 \\
\hline Carbon disulphide & 94.7 & 5.0 & 0.2 & 0.0 & 100.0 & $0.306 \dagger$ \\
\hline Glycol ethers & 75.6 & 18.6 & 4.2 & 1.6 & 100.0 & 0.006 \\
\hline Methylene chloride & 85.8 & 11.3 & 2.2 & 0.7 & 100.0 & 0.744 \\
\hline Styrene & 90.6 & 7.9 & 1.2 & 0.3 & 100.0 & 0.394 \\
\hline Tetrachloroethylene & 92.4 & 5.4 & 1.9 & 0.2 & 100.0 & 0.970 \\
\hline All other VOCs & 65.2 & 25.3 & 7.0 & 2.5 & 100.0 & 0.020 \\
\hline Pesticides & 96.5 & 2.0 & 1.1 & 0.4 & 100.0 & 0.087 \\
\hline Heat & 89.5 & 4.7 & 3.0 & 2.8 & 100.0 & 0.731 \\
\hline Vibration & 66.3 & 17.3 & 10.3 & 6.1 & 100.0 & 0.607 \\
\hline Radiation (non-ionising) & ) 86.9 & 7.6 & 3.5 & 2.1 & 100.0 & 0.344 \\
\hline Radiation (ionising) & 95.1 & 3.1 & 1.5 & 0.3 & 100.0 & 0.805 \\
\hline
\end{tabular}

VOC, volatile organic compound.

Intensity is compared with other occupational exposures in the UK (see text), $\mathrm{n}=2118$.

* In a multi-level logistic regression model to assess relation to case status including: surgery to the testes, previous conception, use of alcohol, and wearing boxer shorts, clustered within centre.

†"High" and "moderate" combined to eliminate empty cells.

f."High", "moderate" and "low" combined to eliminate empty cells.

glycol ether $(p=0.138)$. Conversely glycol ethers did add to a model containing this factor $(p=0.017)$, suggesting that it was exposure to glycol ether as such, rather than simply exposure to any solvent, that was more important in the relation to fertility.

\section{Adjustment for manual work}

Cases were more likely $(54.0 \%$; $472 / 874)$ to be in manual work than referents $(47.8 \%$; 595/1244) (OR $=1.28 ; 95 \%$ CI: 1.08 to 1.52) but inclusion of manual work may serve to reduce the likelihood of detecting exposures that reduce fertility by "overadjusting" the model. For each of the factors rated by the hygienists (except mercury and ionising radiation), exposures were greater in those in manual work. For example the percentage $(10.6 \%$; 113/1067) of those with moderate or high glycol ether exposure in manual work was much higher than those in non-manual work $(0.9 \% ; 9 / 1051)$. Because of this, manual work will act as a proxy where the exposure is omitted from the model (and vice versa), and the presence of both in the same model may tend to reduce the size of effects. When the variable reflecting manual work was added to the model for glycol ethers summarised in Tables 3 and 4 , the significance attributed to glycol ethers was reduced to $p=0.015$ and the corresponding ORs were: low 0.85 (95\% CI: 0.67 to 1.08), moderate 1.46 ( $95 \%$ CI: 0.93 to 2.28 ), high 2.25 (95\% CI: 1.08 to 4.69). The OR associated with manual work was reduced to 1.25 (95\% CI: 1.04 to 1.52). If those with glycol ether exposure (in either manual or non-manual work) were removed from the analysis, those in manual work remained at increased risk (OR $1.27,95 \%$ CI: 1.03 to 1.56 ).

\section{DISCUSSION}

The study was designed to investigate further the observation ${ }^{12}$ that men working in occupations assessed as having a high
Table 4 0dds ratios from logistic regression analysis for exposures assigned by occupational hygienists to the occupation in the 3 months prior to semen sample

\begin{tabular}{|c|c|c|c|c|}
\hline \multirow[b]{2}{*}{ Exposure } & \multicolumn{2}{|l|}{$\mathbf{n}$} & \multirow{2}{*}{$\begin{array}{l}\text { Unadjusted } \\
\text { OR (95\% CI) }\end{array}$} & \multirow{2}{*}{$\begin{array}{l}\text { Adjusted* }^{*} \\
\text { OR (95\% Cl) }\end{array}$} \\
\hline & Cases & Referents & & \\
\hline \multicolumn{5}{|l|}{ Glycol ethers } \\
\hline No & 653 & 949 & 1 & 1 \\
\hline Low & 152 & 242 & 0.91 (0.73 to 1.14$)$ & 0.93 (0.74 to 1.17$)$ \\
\hline Moderate & 48 & 41 & $1.70(1.11$ to 2.61$)$ & 1.65 (1.06 to 2.54$)$ \\
\hline High & 21 & 12 & 2.54 (1.24 to 5.21$)$ & 2.54 (1.23 to 5.27$)$ \\
\hline \multicolumn{5}{|c|}{ All other VOCs } \\
\hline No & 559 & 821 & 1 & 1 \\
\hline Low & 211 & 325 & $0.95(0.78$ to 1.17$)$ & $0.97(0.79$ to 1.19$)$ \\
\hline Moderate & 76 & 73 & 1.53 (1.09 to 2.15$)$ & 1.55 (1.10 to 2.18$)$ \\
\hline High & 28 & 25 & 1.65 (0.95 to 2.85$)$ & $1.68(0.96$ to 2.93$)$ \\
\hline \multicolumn{5}{|c|}{ Carbon disulphide } \\
\hline No & 824 & 1182 & 1 & 1 \\
\hline Low & 46 & 60 & $1.10(0.74$ to 1.63$)$ & $1.13(0.76$ to 1.69$)$ \\
\hline Moderate & 3 & 2 & $2.15(0.36$ to 12.91$)$ & $3.31 \dagger(0.59$ to 18.43$)$ \\
\hline High & 1 & 0 & $\sim$ & \\
\hline \multicolumn{5}{|l|}{ Styrene } \\
\hline No & 786 & 1133 & 1 & 1 \\
\hline Low & 71 & 96 & 1.07 (0.77 to 1.47$)$ & $1.10(0.79$ to 1.52$)$ \\
\hline Moderate & 12 & 13 & 1.33 (0.60 to 2.93$)$ & $1.43(0.64$ to 3.18$)$ \\
\hline High & 5 & 2 & 3.60 (0.70 to 18.62$)$ & 3.12 (0.58 to 16.64$)$ \\
\hline
\end{tabular}

OR, odds ratio; VOC, volatile organic compound.

$\mathrm{n}=2118$.

* In a multi-level logistic regression model including: surgery to the testes, previous conception, use of alcohol and wearing boxer shorts, clustered within centre. $\dagger$ "High" combined with "moderate" to eliminate empty cell.

probability of solvent exposure were at increased risk of a low motile sperm count; it also aimed to identify other exposures that increased risk of poor fertility. The results presented here support the earlier observation, narrowing the exposure from all solvents towards that of glycol ethers. It is of particular note, however, that no other exposure was identified as conveying higher risk, either through the assessment of occupational hygienists, or by report of the subjects themselves. Although all the substances and exposures assessed were included because of some earlier suggestion that they might influence male fertility, apart from the solvents in Table 4, only self-reported driving more than 4 hours/day had a result even suggestive of a greater frequency among men with a low motile sperm count.

The absence of effect of exposures other than solvents/glycol ethers in the assessments made by the occupational hygiene team may indeed reflect a true absence of risk to male fertility for men working in Britain at the turn of the century. The strengths of the study - the standardised and objective assessment of MSC, the absence of recall bias and the blinding of both subject and interviewer to eventual case status, the use of factual and specific job exposure questionnaires and their subsequent blind rating by an experienced hygiene panel - may give support to such an encouraging interpretation. However, although motile sperm count of the ejaculate represents the most significant predictor of male fertility ${ }^{17}$ it must be noted that exposures affecting fertility by other mechanisms (such as altered sperm morphology) would not be identified.

Some other limitations must also be considered. First, the possibilities of selection bias must be considered in the light of the relatively low participation rate ( $53 \%$ of those eligible). The study was, however, designed to minimise differential recruitment by case status, with men deciding to participate or not before they knew the results of their first semen analysis, and the reasons for 
refusal are likely to have been similar in cases and controls. A potentially more important selection effect (on external rather than internal validity) might arise from the decision to accept men into the study only if they had not had a previous semen analysis. We do not know the process by which a family physician decided whether or not such a test was appropriate before making a referral to a local fertility clinic. Although in the UK fertility investigations are available without charge through the national healthcare system, access to treatment, particularly in vitro fertilisation, may be limited by local policies (on age and evidence of a stable partnership, for example); those unlikely to be accepted for treatment (and without the funds to pay privately) may be reluctant to undergo investigations other than, perhaps, a semen analysis arranged through their family physician. However the social class of participants was closely identical to that of men in the 2001 UK census. ${ }^{16}$

Second, the study with 2118 subjects (874 cases) in employment, had power to detect effects only for substances for which some $2 \%$ of the referents had biologically important exposure. As such, the study was not powerful enough to detect small effects in relatively uncommon exposures. The data for styrene and carbon disulphide, for example, are somewhat suggestive of effect but the numbers are too small to draw strong conclusions: even weak data may, however, contribute to the overall body of knowledge on substances rarely studied. Previous results on carbon disulphide and male fertility are mixed, ${ }^{6}{ }^{18}$ possibly reflecting differences in exposure levels. On styrene the literature is indicative of an effect on male fertility ${ }^{19} 2021$ although a recent authoritative review concluded that "there is insufficient evidence in humans that styrene causes reproductive toxicity".22

Third, even for substances where exposures were relatively common in the present study, the intensity may have been too low for any risk to be detected. For example, we found no relation between case status and the hygienists' assessment of lead exposure in the last 3 months but (data not shown) no measured blood lead concentration exceeded $40 \mu \mathrm{g} / \mathrm{dl}$, a value until recently considered an effect threshold. ${ }^{23}$ A recent review suggests $^{24}$ that there is strong epidemiological evidence that some of the exposures self-reported or assessed here (for example heat, ionising radiation, inorganic lead, carbon disulphide and welding) have a deleterious effect on the male reproductive system. It is a limitation of the exposure assessment used in this report, which reflects the hygienist's perception of likely exposure relative to typical UK exposures, that we cannot compare our results with quantitative exposure levels in studies where harmful effects were reported. While estimates of inhalation exposure relative to the threshold limit value were made, the likely high contribution of dermal exposures in work with solvents, including glycol ethers, indicated the use of a less quantitative metric such as that adopted here.

Fourth, misclassification of exposure, with some men with true exposure being classified as unexposed (or some without as exposed) will have biased the size of the exposure effects towards the null. Moreover, the extent of such misclassification may have differed between substances and may perhaps have been lower for glycol ethers than for others, making the detection of an effect more likely. Misclassification of outcome would also reduce the observed relation between low motile sperm and exposure. While great efforts were made to standardise procedures and to reduce measurement error in motility, use of outcomes with less variability (perhaps simply sperm count) might have provided a less attenuated measure of effect.
Finally, there is a possibility of uncontrolled confounding in jobs assessed by the hygienists as entailing exposure to glycol ethers. A "high" rating for glycol ethers was assigned for 33 men who held jobs in 16 categories of the 3-figure UK classification ${ }^{15}$ : only one job, painters and decorators (SOC 507), had more than two men with this "high" assessment; of the 25 painters and decorators, 15 were assessed as being highly exposed to glycol ethers. The analysis presented examined confounding with exposures to other solvents and indicated that it was the glycol ether that had the stronger effect, but the possibility of some confounding by other - unknown - reproductive toxin cannot be excluded.

The relation of glycol ether exposure to low motile sperm count does not appear to explain fully the higher risk of low counts among men in manual work which remained, after allowance for glycol ether exposure, personal habits (alcohol use and type of underwear) and medical history, some 25\% higher than for those in non-manual work. While this might, in part, arise from an under-assessment of true glycol ether exposure, it is likely that there are other differences between those in manual and non-manual work, both in and out of the workplace, that have not been adequately captured by the study; cigarette smoking, although more common in manual workers, was unrelated to case status and did not account for the excess risk in this group. Careful inspection of case status by occupational and industry codes did not help to identify informative subgroups or suggest other exposures, not assessed in this study, that might have been responsible.

The plausibility of the conclusion that glycol ethers were affecting the fertility of those rated with moderate or high exposure depends on the likelihood that these men had been exposed to types of glycol ether that affect testicular function in man. Both propylene glycol ether derivatives and the longer chain ethylene glycol ethers (such as ethylene glycol butyl ether) are thought not to affect the testes. However short chain ethers form toxic metabolites (methoxyacetic acid and ethoxyacetic acid) and are highly toxic to the testes ${ }^{25} 26$ in experimental animals, with epidemiological evidence in man. ${ }^{27-29}$ In the European Union, where the short chain glycol ethers have been classified as toxic to the reproductive system and labelled "may affect fertility" the use of propylene glycol ethers has increased markedly since the 1970s and that of methyl and ethyl derivatives has reduced, such that the two most toxic to the testes (ethylene glycol methyl ether (EGME) and ethylene glycol ethyl ether (EGEE)) formed less than $5 \%$ of the total market for glycol ethers in 2002..$^{30}$ In the present study, as in the previous Belgian and Dutch studies ${ }^{27}{ }^{31}$ only some $5 \%$ of urine samples measured were positive for glycol ether metabolites (data not shown). The level of detection in these studies was however about 20 times less sensitive than in the recently published study of French municipal workers where methoxyacetic acid was found in the urine of $51.1 \%$ of men thought to be currently exposed (in 2000-1) to glycol ethers and $24.5 \%$ of those not currently exposed, with ethoxyacetic acid in the urine of $11.1 \%$ and $5.7 \%$ of men. ${ }^{28}$ Thus despite the documented reductions in both relative and absolute amounts of toxic glycol ether use, low exposures still appear to be widespread. Some of the older men in the current study may have been first employed when high exposures to the more toxic glycol ethers were common but stratification by age did not suggest lower risk in the younger workers (data not shown).

For men rated as having high exposure to glycol ethers risk was more than doubled but the population attributable risk for this chemical group was considerably lower, because of the 


\section{Main messages}

- Few effects of occupation on motile sperm count were found in this multi-centre study designed to standardise methods and minimise reporting bias.

- Occupational exposure to organic solvents, particularly glycol ethers, was associated with an increased risk of low motile sperm count.

- Low motile sperm count was more strongly associated with personal habits and medical history than with glycol ether exposure.

- After allowance for exposures and non-occupational factors, men in manual work remained at increased risk of low motile sperm count.

\section{Policy implication}

The men in the study were in employment after the marked reduction in use of the more toxic glycol ethers that has occurred in Europe since the 1980s. This suggests that glycol ethers continue to be a workplace hazard that warrants scrupulous control measures.

small numbers exposed $(<6 \%)$ at moderate or high levels, than, for example, that associated with wearing tight underwear, a risk factor present in a third of the subjects. Education about such remediable personal habits may be desirable, but the approach is different for occupational hazards where employers and regulatory bodies have a responsibility to protect the worker. The results from the present study suggest that glycol ethers continue to be a workplace hazard and as such may warrant measures to ensure scrupulous control.

Acknowledgements: The study was designed and initiated with the support of Professor lan Cooke of the University of Sheffield. The UK Health and Safety Laboratories (now at Buxton) carried out the analysis of biological samples. The research was made possible by the input from many, in Manchester, Sheffield and in each of the centres forming Chaps-UK. The occupational hygiene panel constituted in addition to authors (GB, MD), Jeff Friar, Lesley Burgess, John Drabble, Dion Froes, Mike Slater and Harry Wilson. The research coordinators and administrative staff included, as well as authors J-A C and HB, Yvonne King, Priscilla Appelbe, Chris Pappas, Deborah Saxton, Ana Roby and Jeanette Tenggren. Technical staff in Manchester and Sheffield included Mark Carus, Kelly Morris, Louise Reeve, Linda Street, Andrew Thomas and Hayley Willis. Each clinical and andrology centre had a team including clinicians, nursing and technical staff, some 70 between the centres and we are greatly indebted for their contributions.

Funding: The study was funded by the UK Health and Safety Executive, the UK Department of Environment, Transport and the Regions, the UK Department of Health and the European Chemical Industry Council. The views expressed are those of the authors and not necessarily those of the funding bodies.

\section{Competing interests: None.}

Ethics approval: Ethical approval was given by the Multi-Centre Ethics Committee for the North West (ref. no. MREC 98/8/73) with subsequent approval given by the Local Research Ethics Committee at each site.

Participating centres of Chaps-UK: Department of Obstetrics and Gynaecology, Queens University, Belfast; Assisted Conception Unit, Birmingham Women's Hospital; Division of Obstetrics and Gynaecology, St Michael's Hospital, Bristol; Directorate of Women's Health, Southmead Hospital, Bristol; Cardiff Assisted Reproduction Unit, University of Wales; MRC Reproductive Biology Unit, Edinburgh; Reproductive Medicine Unit, Liverpool Women's Hospital; St Bartholomew's Hospital, London;
Department of Obstetrics and Gynaecology, Royal Free and University College, London; Department of Reproductive Medicine, St Mary's Hospital, Manchester; IVF/ Immunology Laboratory, Hope Hospital, Salford; Department of Histopathology, Wythenshawe Hospital, Manchester; International Centre for Life, Newcastle; Department of Obstetrics and Gynaecology, Jessop Hospital for Women, Sheffield; Shropshire and Mid-Wales Fertility Centre, Royal Shrewsbury NHS Trust.

\section{REFERENCES}

1. Lancranjan I, Popescu HI, Gavanescu 0, et al. Reproductive ability of workmen occupationally exposed to lead. Arch Environ Health 1975;30:396-401.

2. Whorton D, Kraus RM, Marshall S, et al. Infertility in male pesticide workers. Lancet 1977;2:1259-61.

3. Tas S, Lauwerys R, Lison D. Occupational hazards for the male reproductive system Crit Rev Toxicol 1996;26(3):261-307.

4. Cannon SB, Veazey JM Jr, Jackson RS, et al. Epidemic keptone poisoning in chemical workers. Am J Epidemiol 1978;107:529-37.

5. Ratcliffe JM, Schrader SM, Steenland K, et al. Semen quality in papaya workers with long term exposure to ethylene dibromide. Br J Ind Med 1987;44:317-26.

6. Lancranjan I, Popescu HI, Klepsch I. Changes of the gonadic function in chronic carbon disulfide poisoning. Med Lavoro 1969:60:566-73.

7. Figà-Talamanca I, Dell'Orco V, Pupi A, et al. Fertility and semen quality of workers exposed to high temperatures in the ceramics industry. Reprod Toxicol 1992;6:517-23.

8. Sas M, Szollosi J. Impaired spermiogenesis as a common finding among professional drivers. Arch Androl 1979;3:57-60.

9. Carlsen E, Giwercman A, Keiding N, et al. Evidence for decreasing quality of semen during past 50 years. Br Med J 1992;305:609-13.

10. Jensen TK, Toppari J, Keiding N, et al. Do environmental estrogens contribute to the decline in male reproductive health? Clin Chem 1995;41(12 Pt 2):1896-901.

11. Eskenazi B, Wyrobek AJ, Fenster $L$, et al. A study of the effect of perchloroethylene exposure on semen quality in dry cleaning workers. Am J Ind Med 1991;20:575-91.

12. Cherry NM, Labreche F, Collins J, et al. Occupational exposure to solvents and male infertility. Occup Environ Med 2001:58:635-40.

13. World Health Organization. Laboratory manual for the examination of human semen and semen-cervical mucus interaction, 1st ed. Singapore: Press Concern, 1980.

14. World Health Organization. WHO laboratory manual for the examination of human semen and sperm-cervical mucus interaction, 4th ed. Cambridge, UK: Cambridge University Press, 1999.

15. Office of Population Censuses and Surveys. Standard occupational classification London: HMSO, 1990

16. Clyma JA. Lifestyle and health factors and the risk of male infertility. PhD Thesis University of Manchester, 2004.

17. Larsen L, Scheike T, Jensen TK, et al. Computer-assisted semen analysis parameters as predictors for fertility of men from the general population. Hum Reprod 2000;15:1562-7.

18. Meyer CR. Semen quality in workers exposed to carbon disulphide compared to a control group from the same plant. J Occup Med 1981;23:566-73.

19. Jelnes JE. Semen quality in workers producing reinforced plastic. Reprod Toxicol 1988;2:209-12

20. Kolstad HA, Bonde JP, Spano M, et al. Change in semen quality and sperm chromatin structure following occupational styrene exposure. Int Arch Occup Environ Health 1999;72:135-41.

21. Migliore L, Naccarati A, Zanello A, et al. Assessment of sperm DNA integrity on workers exposed to styrene. Hum Reprod 2002;17:2912-18.

22. National Toxicology Program, Centre for the Evaluation of Risks on Human Reproduction. NTP-CERHR Monograph on the Potential Human Reproductive and Developmental Effects of Styrene. NIH Publication No. 06-4475 2006. US Department of Health and Human Services.

23. Bonde JP, Apostoli P. Any need to revisit the male reproductive toxicity of lead? Occup Environ Med 2005:62:2-3.

24. Jensen TK, Bonde JP, Joffe M. The influence of occupational exposure on male reproductive function. Occup Med 2006:56:544-53.

25. European Centre for Ecotoxicology and Toxicology of Chemicals. The toxicology of glycol ethers and its relevance to man, 4th ed. ECETOC technical report No. 95. Brussels, Belgium, 2005.

26. Multigner L, Catala M, Cordier S, et al. The INSERM expert review on glycol ethers: findings and recommendations. Toxicol Lett 2005;156:29-37.

27. Veulmans H, Steeno 0, Masschelein R, et al. Exposure to ethylene glycol ethers and spermatogenic disorders in man: a case-control study. BJIM 1993;50:71-8.

28. Multigner L, Ben Brik E, Arnaud I, et al. Glycol ethers and semen quality: a cross sectional study among male workers in the Paris Municipality. Occup Environ Med 2007:64:467-73.

29. Welch LS, Schrader SM, Turner TW, et al. Effects of exposure to glycol ethers on shipyard painters: II. Male reproduction. Am J Ind Med 1988;14:509-26.

30. de Ketttenis $\mathbf{P}$. The historic and current use of glycol ethers: a picture of change Toxicol Lett 2005;156:5-11.

31. Tielemans $\mathbf{E}$, Burdorf A, te Velde ER, et al. Occupationally related exposures and reduced semen quality: a case-control study. Fertil Steril 1999:71:690-6. 